\title{
Interannual Variability of the Tropical Cyclone Landfall Frequency over the Southern and Northern Regions of East Asia in Autumn
}

\author{
XINGYAN ZHOU \\ Laboratory for Climate Studies, National Climate Center, China Meteorological Administration, Beijing, China \\ RIYU LU \\ LASG, Institute of Atmospheric Physics, Chinese Academy of Sciences, and College of Earth and Planetary Sciences, \\ University of the Chinese Academy of Sciences, Beijing, China
}

(Manuscript received 22 January 2019, in final form 28 August 2019)

\begin{abstract}
This study focused on the interannual variability of tropical cyclone (TC) activity over the western North Pacific in autumn. The results show that the frequencies of TC landfalls in the southern and northern coastal regions of East Asia are roughly independent, implying that they are affected by different factors and should be studied separately. Further analysis indicates that the frequency of TC landfall in the southern region is closely related to El Niño-Southern Oscillation, which affects both the upper- and lower-tropospheric circulation over the western North Pacific and East Asia and induces changes in the steering flow. By contrast, the frequency of TC landfall over the northern region has a close connection with a teleconnection pattern in the upper troposphere over the Eurasian continent, which seems to be triggered by an anomalous Rossby wave source over the North Atlantic. This teleconnection pattern leads to anomalous meridional winds over the western North Pacific and East Asia and induces significant changes in the steering flow.
\end{abstract}

\section{Introduction}

Tropical cyclones (TCs), as the worst natural disasters, cause huge human and property losses through strong winds, torrential rainfall, and tidal surges during or after landfall (e.g., Zhang et al. 2009; Park et al. 2011; Corporal-Lodangco et al. 2016). The western North Pacific (WNP) spawns the most TCs of all the ocean basins, accounting for more than one-third of all TCs globally (e.g., Wu and Wang 2004). In addition, East Asia is home to about a quarter of the world's population, with a large percentage living in coastal regions. It is therefore essential to gain a better understanding of the variability of TCs making landfall over East Asia.

The location at which a TC makes landfall is mainly determined by its track. Previous studies have identified three prevailing types of track over the WNP: a straightmoving (or westward-moving) track, a recurvinglandfall track, and a recurving-ocean track (e.g., Elsner and Liu 2003; Wu et al. 2005; Camargo et al. 2007a,b;

Corresponding author: Xingyan Zhou, zhouxingyan@cma.gov.cn
Kim et al. 2011; Colbert et al. 2015; He et al. 2015; Mei and Xie 2016). Straight-moving TCs tend to make landfall in the southern coastal region (the Philippines, Vietnam, and southern China), whereas recurving TCs threaten the northern coastal region (eastern China, the Korean Peninsula, and Japan) or disperse over the ocean without making landfall. Hence the frequency of TC landfall over East Asia can be separated into the two types: those making landfall in the southern coastal region and those making landfall in the northern coastal region, almost corresponding to the TCs with straightmoving and recurving tracks, respectively. The variation in the TC track is significantly influenced by the steering flow (Riehl and Burgner 1950; Chan and Gray 1982; Fiorino and Elsberry 1989; Wu and Emanuel 1995; Wu and Chen 2016).

Interannual variation of TC landfall frequency has great socioeconomic impacts on East Asia. Anomalously high frequency of TC landfall in a particular typhoon season can threaten livelihoods of people in East Asia, especially in the heavily populated coastal areas. Anomalously low frequency of TC landfall, by contrast, may also induce negative effects such as shortage of 
water resources. Therefore, the interannual variation of TC landfall frequency has attracted great attention (e.g., Liu and Chan 2003; Wu et al. 2004; Fudeyasu et al. 2006; Goh and Chan 2010; Zhang et al. 2012; Gao et al. 2018; Wang and Chen 2018).

Sea surface temperature (SST) anomalies can affect the tracks and locations of TC landfalls over the WNP on the interannual time scale. Previous studies have shown that El Niño-Southern Oscillation (ENSO) exerts a great influence on the track and landfall of TCs (Elsner and Liu 2003; Liu and Chan 2003; Wu et al. 2004; Chu 2004; Zhang et al. 2012). According to these studies, during La Niña years, the easterly steering flow over the tropical WNP is enhanced, and TCs tend to be generated farther westward, both favoring a straight track and landfall in South China, the Philippines, and the Malaysian Peninsula. Furthermore, Gao et al. (2018) suggested that SST anomalies in the tropical North Atlantic can also affect the TC landfalls over East Asia: negative SST anomalies in this region favor TC landfalls over Vietnam, China, the Korean Peninsula, and Japan. While these studies focused on the tropical impacts on the interannual variability of TC landfall frequency over East Asia, the extratropical factors affecting TC landfall have been ignored. Whether and how extratropical circulation patterns affect TC landfall over East Asia is one of motivations of this study.

TCs over the WNP are mainly active in summer and autumn. However, TC activities are remarkably different between these two seasons, and there are distinct discrepancies in the mechanisms responsible for the interannual variability of summer and autumn TC activities. Previous studies have identified significant relationships between summer TC activity and PacificJapan pattern (Choi et al. 2010; Kim et al. 2012), Antarctic Oscillation (Wang and Fan 2007), and SSTs in the Indian Ocean and tropical Pacific (Liu et al. 2019; Wang and Chen 2018). Due to the significant relationships with tropical circulations and SSTs, summer TC activity can be well predicted (Wang et al. 2013; Camp et al. 2019). As for autumn TCs, Wu et al. (2004) found that the TC landfall activity over the WNP is significantly related to SST anomalies in the equatorial central and eastern Pacific only in autumn, but not in summer. All these previous studies suggested the differences in the interannual variability between summer and autumn, and different physical mechanisms responsible for variability. Therefore, a separate investigation of TC activity in these two seasons may help us gain a better understanding of interannual variability in TC activity over the WNP. In this study, we focus on the interannual variability of autumn TC activity, which has not been well documented compared to summer TCs.
The TC landfalls over the WNP show a wide range of latitudes. As mentioned above, they can be separated into the landfalls in the southern and northern coastal regions, respectively. Are there any differences in the interannual variabilities of TC landfall frequency between southern and northern regions in autumn? If so, do they have different physical mechanisms? These questions are also the motivation of this study.

This paper is organized as follows. Section 2 presents the data and methods. Section 3 describes the interannual variations in TC landfall frequency over the WNP. Section 4 discusses the possible factors responsible for interannual variations in the landfall frequency. Our conclusions are presented in section 5 .

\section{Data and methods}

The monthly horizontal winds are from the National Centers for Environmental Prediction-National Center for Atmospheric Research (NCEP-NCAR) reanalysis dataset for the time period 1958-2014 with a horizontal resolution of $2.5^{\circ} \times 2.5^{\circ}$. The SST data are from the Extended Reconstructed Sea Surface Temperature, version 4 (ERSSTv4), dataset with a horizontal resolution of $2^{\circ} \times 2^{\circ}$. The Niño-3.4 index is defined as the SST anomalies averaged over the region $5^{\circ} \mathrm{S}-5^{\circ} \mathrm{N}, 120^{\circ}-$ $170^{\circ} \mathrm{W}$. We focus on the autumn season, which is defined as September-November (SON).

The TC data are from the Joint Typhoon Warning Center with a 6-hourly interval (www.metoc.navy.mil/ jtwc/jtwc.html). We selected tropical storms with a maximum surface wind speed $\geq 34 \mathrm{kt}\left(17 \mathrm{~m} \mathrm{~s}^{-1}\right)$. Although some of the TC activity might not have been detected before the weather satellite era, it would only slightly affect the results since the majority of the study period is from the 1960s onward. In addition, the choice of tropical storms may lessen the errors possibly arising from the change in TC detection technique (e.g., Wang and Chan 2002). The frequency of occurrence of TCs is counted in each $5^{\circ} \times 5^{\circ}$ latitude-longitude grid. The TCs are defined as making landfall if their centers cross the coastline. At the time of landfall, the TCs are required to be of at least tropical storm intensity or higher. The values of TC-related parameters (including the frequency of occurrence, track, and number making landfall) are defined as the sum of each parameter during SON.

\section{Interannual variability of the number of TCs making landfall over East Asia during autumn}

Figure 1 shows the spatial distribution of the 58-yr mean frequency of occurrence of autumn TCs, which is 


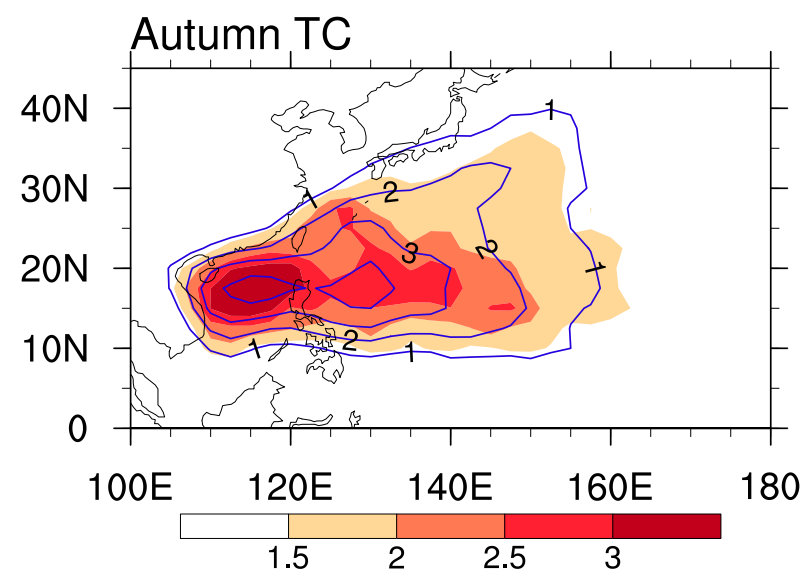

FIG. 1. Climatology (contours) and interannual standard deviation (shading) of the frequency of occurrence of TCs during the time period 1958-2014 in autumn $\left(\mathrm{yr}^{-1}\right)$.

primarily a reflection of the motion of TCs (e.g., Wu and Wang 2004). TCs mainly appear in the South China Sea (SCS) and tropical WNP, indicating a prevailing track of straight-moving TC. The strongest interannual variability of the frequency of TC occurrence appears over the SCS.

To further illustrate the regional features of the interannual variability of the frequency of occurrence of TCs in autumn, we compared the relationship between the frequency of occurrence of TCs in the SCS, where there is the strongest variability, and other regions. Figure 2a shows the variation in the frequency of occurrence of TCs in autumn averaged over the SCS $\left(10^{\circ}\right.$ $\left.22.5^{\circ} \mathrm{N}, 110^{\circ}-122.5^{\circ} \mathrm{E}\right)$, denoted here as the SCS index. The frequency of occurrence of TCs in the SCS shows a decadal variation, with an above-normal frequency of occurrence from the mid-1960s to the mid-1970s and from the mid-1980s to the mid-1990s and a belownormal frequency of occurrence since the mid-1990s.
The interannual variability is dominant, however, and, if defined as the residual remaining after removing the 9-yr running mean, explains $85 \%$ of the total variance. Therefore, we analyzed the original time series without removing long-term variations.

Figure $2 b$ shows the distribution of correlation coefficients between the SCS index and the frequency of occurrence of TCs on the grids of the WNP. Positive correlations appear in the SCS and extend southeast into the tropical WNP. There is no significant correlation in other regions, with only sporadic regions of negative and weak correlation over the subtropical WNP. This indicates that the TC activity over the SCS has no significant connection with that over the subtropical WNP.

Figure 3 shows the composite TC tracks during the years with anomalously high and low numbers of TCs in the SCS. These years are selected according to the SCS index being higher or lower than one standard deviation. The 9 years with anomalously high number of TCs in the SCS include 1964, 1970, 1973, 1974, 1985, 1986, 1991, 1995, and 1996, and the 9 years with anomalously low number of TCs in the SCS include 1958, 1961, 1963, 1969, 1976, 1997, 2002, 2004, and 2014. As expected, the number of straight-moving TCs during the years with anomalously high number of TCs in the SCS is much greater than that during the years with anomalously low number of TCs.

Table 1 gives mean counts of TCs with straightmoving and recurving tracks averaged over the years with anomalously high and low numbers of TCs in the SCS. A straight-moving (recurving) TC is simply defined as a TC with its extinction latitude lower (higher) than $25^{\circ} \mathrm{N}$. Here, the TC extinction latitude is defined as the latitude where a TC's intensity is lower than $34 \mathrm{kt}$ $\left(17 \mathrm{~m} \mathrm{~s}^{-1}\right)$. Although the extinction latitudes do not guarantee whether TCs move straight or recurve, there is a good agreement between the extinction latitudes (a) SCS TC occurrence

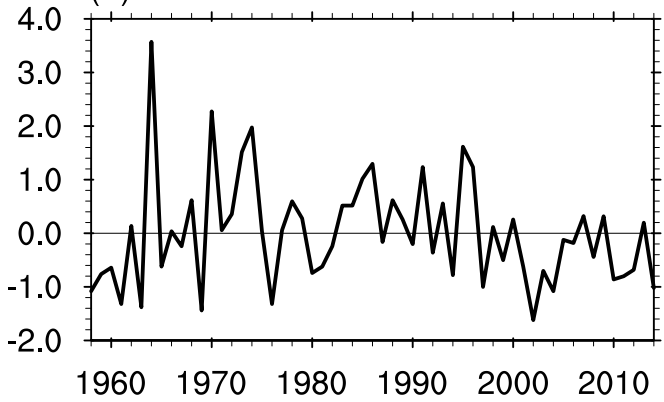

(b) Correlation distribution

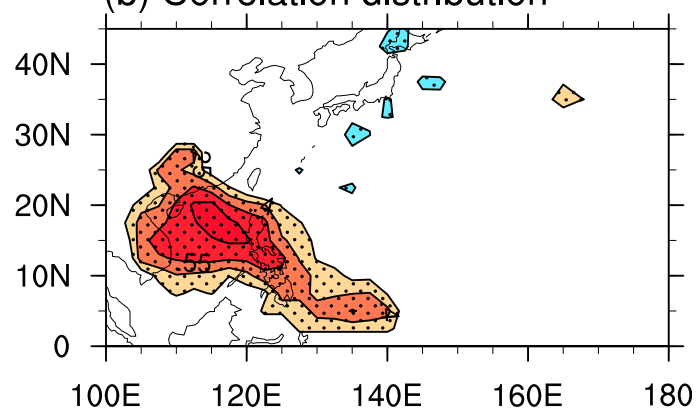

FIG. 2. (a) Normalized frequency of occurrence of TCs averaged over the SCS $\left(10^{\circ}-22.5^{\circ} \mathrm{N}, 110^{\circ}-122.5^{\circ} \mathrm{E}\right)$ and (b) correlation coefficients between the SCS index and the frequency of occurrence of TCs on the grids of the WNP.

Dots denote regions that are significant at the $95 \%$ confidence level. 
(a) TC track_High number years

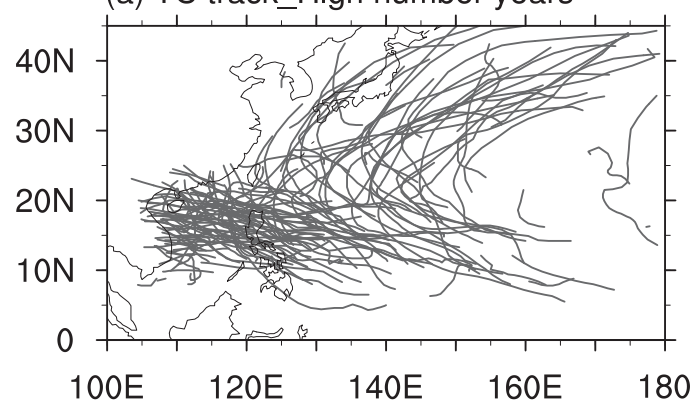

(b) TC track_Low number years

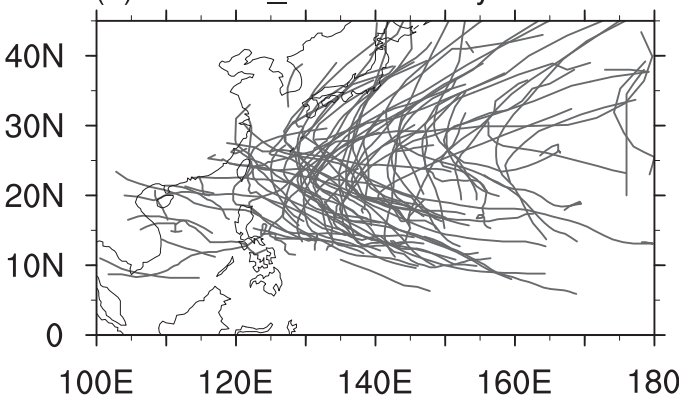

FIG. 3. Composite TC tracks during the years with anomalously (a) high and (b) low numbers of TCs in the SCS.

and tracks. For instance, we have examined all the tracks of 321 TCs whose extinction latitudes are lower than $25^{\circ} \mathrm{N}$ during the entire analysis period, and we found that about $90 \%$ of them show straight-moving tracks (not shown). We also used other latitudes (e.g., $23^{\circ}$ or $27^{\circ} \mathrm{N}$ ) as the critical latitude and obtained similar results. The numbers of straight-moving TCs averaged over the years with anomalously high and low numbers of TCs in the SCS are 9.1 and 3.0, respectively, and the difference between them is statistically significant at the $99 \%$ confidence level. By contrast, there is no significant difference in the number of recurving TCs between the years with anomalously high and low numbers of TCs in the SCS. This shows that, during the years with anomalously high number of TCs in the SCS, the significant increase in the frequency of straight-moving TCs is not accompanied by a pronounced decrease in the frequency of recurving TCs, suggesting that the frequency of straight-moving TCs is roughly independent of the frequency of recurving TCs. This is consistent with the weak association between the frequency of occurrence of TCs over the SCS and that over the subtropical WNP (Fig. 2b). Considering the close relationship between the track of TCs and the location of landfall, the insignificant link between the frequencies of straight-moving and recurving TC suggests that the numbers of TCs making landfall in the southern and northern regions are mutually independent in autumn.

Figure 4a shows the locations of TC landfall over East Asia in autumn during the time period of 1958-2014.
Based on previous studies (e.g., Kim et al. 2008; R. C. Li et al. 2017; Zhou et al. 2018), we divided East Asia into southern and northern regions at the latitude of $25^{\circ} \mathrm{N}$, in agreement with the classification criterion of straightmoving and recurving TC tracks. Taiwan Island is excluded from the statistics because roughly the same numbers of straight-moving and recurving TCs affect the island. Figure $4 \mathrm{~b}$ shows the variations in the frequency of TC landfall in the southern and northern regions. The frequency of landfall in the southern region is usually greater than that in the northern region, consistent with the higher frequency of occurrence of TCs in the tropical WNP relative to the subtropical WNP (Fig. 1). Hereafter, the landfall frequencies in the southern and northern regions are referred to as the south and north TC indices, respectively. These two indices have a weak correlation coefficient $(-0.05)$, implying that the factors influencing the frequencies of autumn landfall in the southern and northern regions are clearly distinct.

\section{Possible factors affecting TC landfall in the southern and northern regions}

Figure 5 shows the regression of the steering flows with respect to the normalized south and north TC indices. Here, the steering flow is defined as the pressureweighted mean flow from 850 to $300 \mathrm{hPa}$ (e.g., Holland 1993; He et al. 2015). There are significant easterly anomalies extending from the tropical WNP westward

TABLE 1. Mean counts of TCs with straight-moving and recurving tracks averaged over years with anomalously high and low numbers of TCs in the SCS $\left(\mathrm{yr}^{-1}\right)$. Two asterisks indicates a difference that is significant at the $99 \%$ confidence level.

\begin{tabular}{lcr}
\hline \multicolumn{1}{c}{ Variable } & No. of straight-moving TCs & No. of recurving TCs \\
\hline Anomalously high number of TCs in the SCS & 9.1 & 5.3 \\
Anomalously low number of TCs in the SCS & 3.0 & 6.4 \\
Difference & $6.1^{* *}$ & -1.1 \\
\hline
\end{tabular}


(a) TC landfall distribution

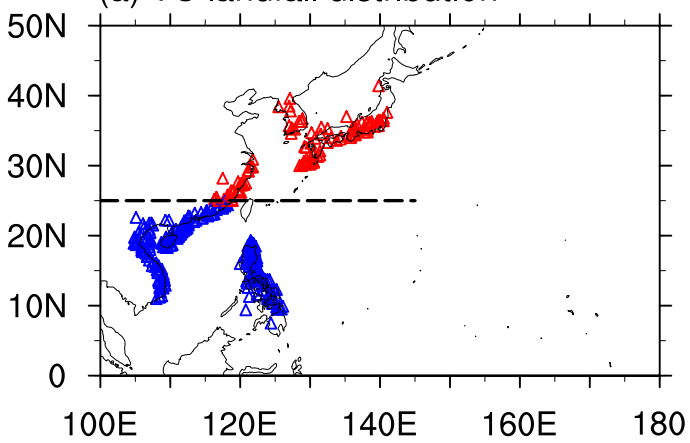

(b) TC landfall frequency

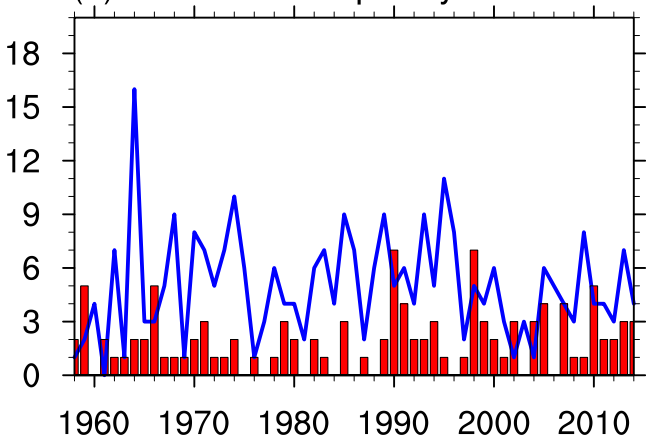

FIG. 4. (a) Locations of landfall of TCs over the WNP and (b) frequencies of landfall of TCs in the southern (blue line) and northern (red bars) regions in autumn during time period 1958-2014. The blue (red) triangles in (a) denote the locations of landfall of TCs in the southern (northern) region.

to southern China and Indochina for the southern landfall frequency. These anomalous steering flows favor a straight-moving track for TCs, which therefore make landfall over the southern region. By contrast, the steering flows associated with the northern landfall frequency are characterized by anomalous southeasterly winds over the extratropical WNP and southwesterly winds over the tropical WNP, which favor a recurving track and TC landfall in the northern region. These steering-flow anomalies can therefore be used to explain the anomalous TC tracks and landfalls for both the southern and northern regions.

To investigate the mechanisms leading to the formation of the anomalous steering flows, we examined the corresponding large-scale circulation anomalies at particular pressure levels. We started with the southern TC landfall. Figure 6 shows the regression of the 300- and 850-hPa horizontal winds with respect to the normalized south TC index. There is an anticyclonic anomaly over eastern China and a cyclonic anomaly to the east of Japan (Fig. 6a), which resemble the steering-flow anomalies over the subtropical and midlatitude WNP (Fig. 5a). The upper-tropospheric wind anomalies show a wave train from East Asia to the North Pacific and North America, with a moderate significance over the North Pacific and North America. At $850 \mathrm{hPa}$, the wind anomalies are featured by a significant cyclonic anomaly around the SCS, similar to the steering-flow anomalies over the tropical WNP (Fig. 5a). Therefore, both the upper- and lower-tropospheric circulation anomalies contribute to the formation of the easterly steering-flow anomalies extending from the tropical WNP westward to southern China, which favor the landfall of TCs over the southern region. There are also westerly and easterly anomalies in the tropical Pacific at 300 and $850 \mathrm{hPa}$, respectively, suggesting an enhanced (a) Steering flow_south TC

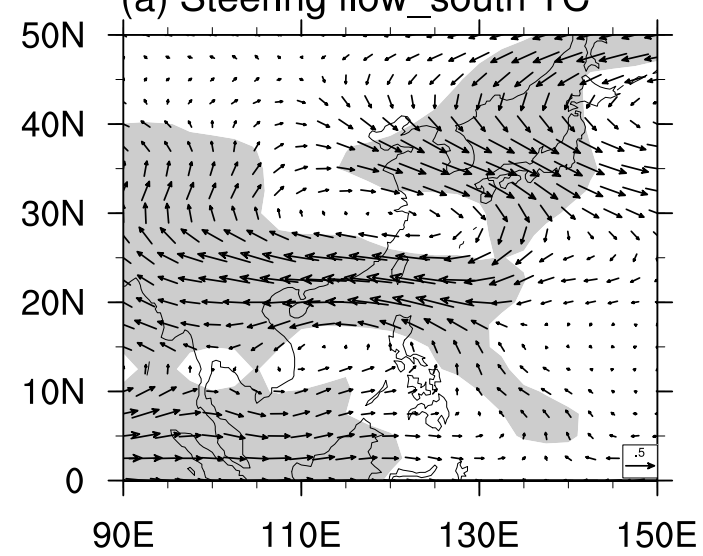

\section{(b) Steering flow_north TC}

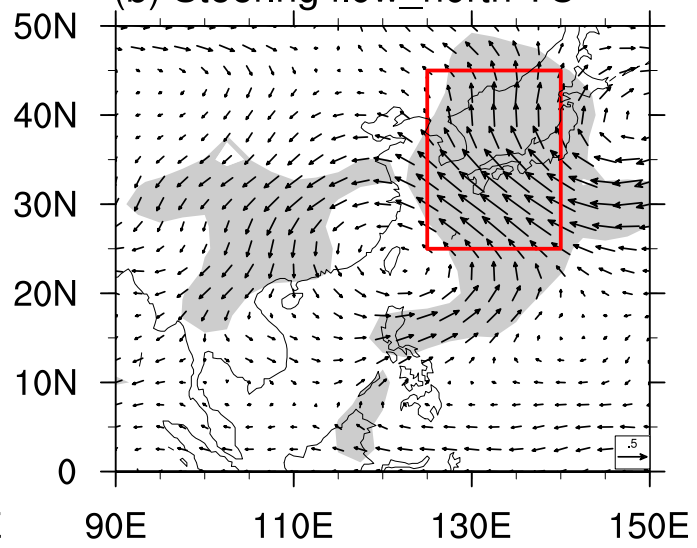

FIG. 5. Regression of the steering flows (vectors; $\mathrm{m} \mathrm{s}^{-1}$ ) with respect to the normalized (a) south and (b) north TC indices during autumn. Shading denotes regions of either the zonal or meridional components that are significant at the $95 \%$ confidence level. The red rectangle in (b) represents the defined region of the steering-flow index (SFI). 
(a) 300wind_south TC

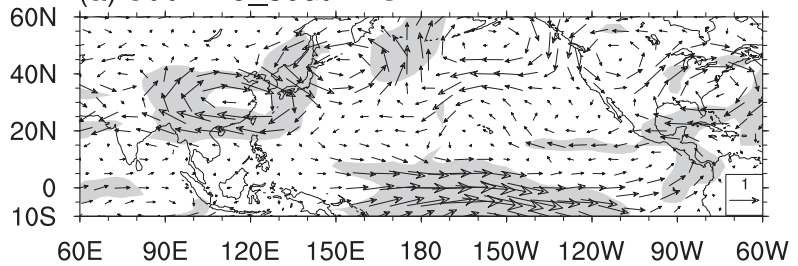

(b) 850wind_south TC

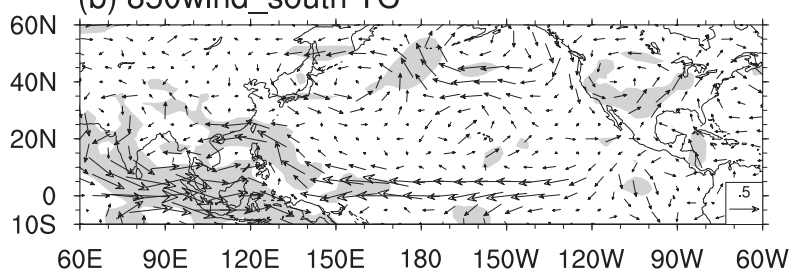

FIG. 6. Regression of the (a) 300- and (b) 850 -hPa horizontal winds $\left(\mathrm{m} \mathrm{s}^{-1}\right)$ with respect to the normalized south TC index during autumn. Shading denotes regions of either zonal or meridional wind anomalies that are significant at the $95 \%$ confidence level.

Walker circulation and a possible relationship between the frequency of landfall in the southern region and SST anomalies in the tropical Pacific.

Figure 7 shows the regression of the SST and $500-\mathrm{hPa}$ vertical velocity (omega) onto the normalized south TC index. The SST anomalies in the tropical Pacific show a La Niña pattern with a cold anomaly in the equatorial central and eastern Pacific and a warm anomaly in the western Pacific and Maritime Continent (Fig. 7a). The correlation coefficient between the south TC index and the Niño-3.4 index is -0.37 , significant at the $99 \%$ confidence level. There are strong ascending anomalies over the tropical western Pacific, including the Maritime Continent and the SCS, and descending anomalies in the equatorial central Pacific (Fig. 7b). These vertical velocity anomalies are in good agreement with the SST anomalies, that is, the positive and negative SST anomalies correspond to the ascending and descending anomalies, respectively. This suggests that the ocean plays an active part in atmosphere-ocean interactions (e.g., Wu et al. 2006; Kumar et al. 2013). Both the SST and vertical velocity anomalies are consistent with the enhanced Walker circulation shown in Fig. 6. There are also negative SST anomalies in the Indian Ocean and tropical North Atlantic. However, there is no significant descending anomaly over these regions, implying that these SST anomalies play a much weaker part in inducing atmospheric anomalies than the Pacific SST anomalies.

The vertical velocity anomalies, which can be considered as a proxy for precipitation and the resultant latent heating anomalies, can also be used to explain the (a) SST south TC

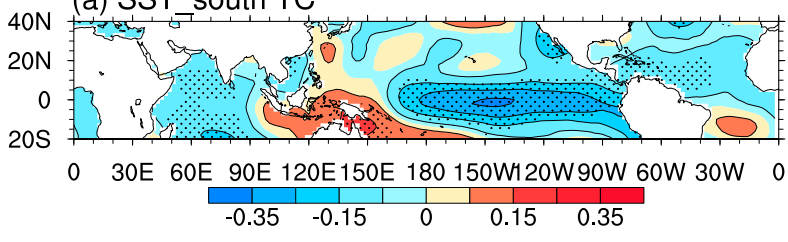

(b) 500omega south TC

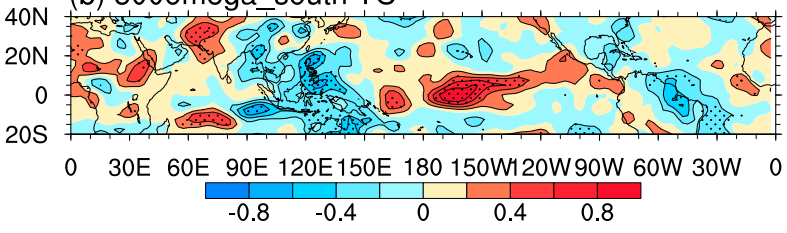

FIG. 7. Regression of (a) the SST $\left({ }^{\circ} \mathrm{C}\right.$ ) and (b) the $500-\mathrm{hPa}$ omega $\left(10^{-2} \mathrm{~m} \mathrm{~s}^{-1}\right)$ with respect to the normalized south TC index. The dots denote regions that are significant at the $95 \%$ confidence level.

circulation anomalies in remote regions. The heating anomaly over the tropical western Pacific and Maritime Continent, implied by the ascending anomalies, may induce a lower-tropospheric cyclonic anomaly over the SCS, Indochina Peninsula, and the Bay of Bengal as a Rossby wave response to heating (Fig. 6b). This tropical heating anomaly may also be responsible for the uppertropospheric wave train from East Asia to North America, through a mechanism similar to the formation of the Pacific-Japan or East Asia-Pacific teleconnection pattern in summer (Nitta et al. 1986; Nitta 1987; Huang and Li 1987; Kurihara and Tsuyuki 1987). The response of the extratropical circulation to tropical heating forces may be different between autumn and summer, but specific research on this issue is beyond the scope of this study.

The steering flows associated with the frequency of northern landfall are characterized by anomalous southerlies over the subtropical WNP (Fig. 5b). To further examine the large-scale circulation anomalies associated with these anomalous steering flows, we defined a steering-flow index (SFI) as the normalized meridional component of the steering flow averaged over the region $25^{\circ}-45^{\circ} \mathrm{N}, 125^{\circ}-140^{\circ} \mathrm{E}$ (see the red rectangle in Fig. $5 \mathrm{~b}$ ). The correlation coefficient between this index and the frequency of northern landfall is 0.48 , significant at the $99 \%$ confidence level, confirming the close link between the steering flow over the WNP and the frequency of northern landfall.

Figure 8 shows the regression of $300-\mathrm{hPa}$ horizontal winds with respect to the normalized SFI. Southerly anomalies appear over the WNP and East Asia and are associated with the anomalous anticyclone centered to the east of Japan and the cyclone centered over central and eastern China. There is also a cyclonic anomaly centered at about $50^{\circ} \mathrm{E}$ and an anticyclonic anomaly of 


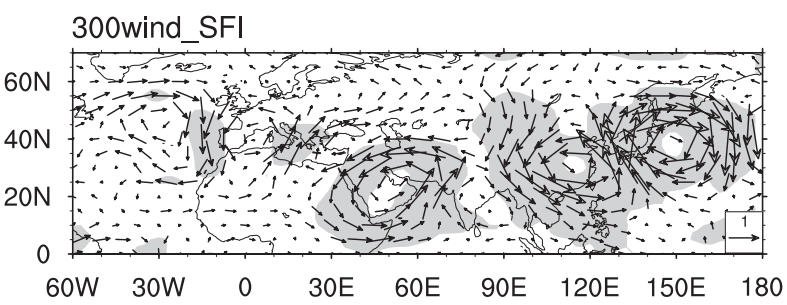

FIG. 8. Regression of the $300-\mathrm{hPa}$ horizontal winds $\left(\mathrm{m} \mathrm{s}^{-1}\right)$ with respect to the normalized SFI. Shading denotes regions of either zonal or meridional wind anomalies that are significant at the $95 \%$ confidence level.

relatively weak amplitude located at about $80^{\circ} \mathrm{E}$. An anticyclonic anomaly and a cyclonic anomaly appear over the North Atlantic and western Mediterranean, respectively, with a moderate significance level. All these anomalous anticyclones and cyclones appear as a wavelike pattern from the North Atlantic to East Asia.

To further examine this wavelike pattern, we defined an upstream index (UpI) as the difference between 300$\mathrm{hPa}$ meridional winds averaged over two regions, that is, $300 V_{\left(10^{\circ}-25^{\circ} \mathrm{N}, 62.5^{\circ}-67.5^{\circ} \mathrm{E}\right)}$ minus $300 V_{\left(10^{\circ}-25^{\circ} \mathrm{N}, 27.5^{\circ}-32.5^{\circ} \mathrm{E}\right)}$. The UpI-related $300-\mathrm{hPa}$ horizontal wind anomalies (Fig. 9) are similar to the SFI-related anomalies (Fig. 8). The UpI-related wind anomalies also show a wavelike pattern from the North Atlantic to East Asia. This wave train is roughly aligned along the upper-level westerly jet, represented by the red contour lines in Fig. 9. Rossby waves can propagate eastward along the westerly jets, which act as waveguides according to the theory of Hoskins and Ambrizzi (1993), and previous observational studies, despite for summer situations, have shown a teleconnection pattern along the Asian uppertropospheric westerly jet (e.g., Lu et al. 2002; Enomoto 2004; Hong and Lu 2016; Hong et al. 2018). Based on these results, we conclude that the upstream wind anomalies affect the downstream steering-flow anomalies and frequency of TC landfall over the northern region through a teleconnection along the westerly jet. This is supported by the significant correlation coefficients between the UpI, SFI, and north TC index (Table 2).

Figure 10 shows the regression of the $300-\mathrm{hPa}$ Rossby wave source with respect to the normalized UpI. The definition of linear Rossby wave source (RWS) refers to Sardeshmukh and Hoskins (1988), that is, RWS $=-\nabla_{H} \cdot\left[\mathbf{u}_{\chi}^{\prime}(f+\bar{\zeta})\right]-\nabla_{H} \cdot\left(\overline{\mathbf{u}}_{\chi} \zeta^{\prime}\right)$. Here, $\mathbf{u}_{\chi}=$ $\left(u_{\chi}, v_{\chi}\right)$ are the divergent wind components, $\zeta$ denotes relative vorticity and $f$ is Coriolis parameter. The overbar and the prime denote the climatological mean and the perturbation associated with the upstream index, respectively. The first term on the right-hand side of the equation is the stretching term representing the

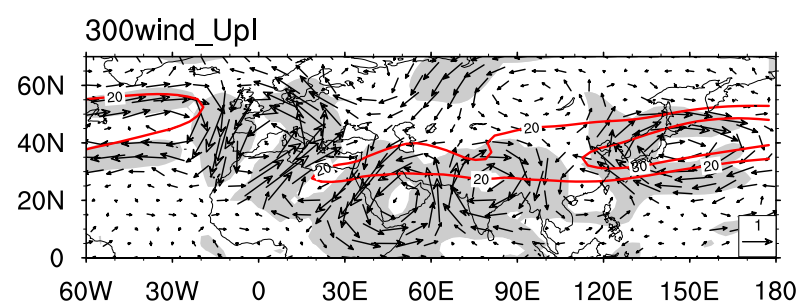

FIG. 9. Regression of the $300-\mathrm{hPa}$ horizontal winds $\left(\mathrm{m} \mathrm{s}^{-1}\right)$ with respect to the normalized upstream index $(\mathrm{UpI})$, i.e., $\mathrm{UpI}=$ $300 V_{\left(10^{\circ}-25^{\circ} \mathrm{N}, 62.5^{\circ}-67.5^{\circ} \mathrm{E}\right)}-300 V_{\left(10^{\circ}-25^{\circ} \mathrm{N}, 27.5^{\circ}-32.5^{\circ} \mathrm{E}\right)}$. Red contours represent the climatology of autumn 300-hPa zonal wind $\left(\mathrm{m} \mathrm{s}^{-1}\right)$. Shading denotes regions of either zonal or meridional wind anomalies that are significant at the $95 \%$ confidence level.

convergence or divergence of the flow. The second term is the advection term denoting the vorticity advection by the divergent wind. There is a positive and significant RWS anomaly over the mid- to high-latitude North Atlantic, which is the most upstream one among all RWS anomalies. We thus defined the RWS averaged over $50^{\circ}-65^{\circ} \mathrm{N}, 0^{\circ}-25^{\circ} \mathrm{W}$ (see the red rectangle in Fig. 10) as the RWS index (RWSI). This index shows a high correlation with the UpI and is also significantly related to both the SFI and the north TC index (Table 2). In addition to the North Atlantic, there are also other RWS anomalies in the midlatitudes, but they are much weaker. Therefore, we suggest that the RWS over the North Atlantic may trigger the wave train over Eurasia and thus affect the steering flows and frequency of northern landfall. We further analyzed the regression of the stretching and advection terms with respect to the normalized upstream index, and we found that the anomalous RWS is mainly contributed by the stretching term (not shown), suggesting that the RWS is closely linked to the divergence or convergence in the upper troposphere.

We also examined the summertime relationship between the teleconnection pattern along the Asian westerly jet and the frequency of TC landfall in East

TABLE 2. Correlation coefficients among the RWSI (RWS averaged over $50^{\circ}-65^{\circ} \mathrm{N}, 0^{\circ}-25^{\circ} \mathrm{W}$ ), the UpI (difference between $300-\mathrm{hPa}$ meridional winds averaged over two regions $\left[300 V_{\left(10^{\circ}-25^{\circ} \mathrm{N}, 62.5^{\circ}-67.5^{\circ} \mathrm{E}\right)}\right.$ minus $300 V_{\left(10^{\circ}-25^{\circ} \mathrm{N}, 27.5^{\circ}-32.5^{\circ} \mathrm{E}\right)}$ ), the SFI (normalized meridional component of the steering flow averaged over $25^{\circ}-45^{\circ} \mathrm{N}, 125^{\circ}-140^{\circ} \mathrm{E}$ ), and the north TC index (landfall frequency of the northern region). One asterisk (two asterisks) denotes a correlation coefficient that is significant at the $95 \%$ (99\%) confidence level.

\begin{tabular}{lccc}
\hline \hline Index & UpI & SFI & North TC index \\
\hline RWSI & $0.55^{* *}$ & $0.31^{*}$ & $0.27^{*}$ \\
UpI & - & $0.53^{* *}$ & $0.34^{* *}$ \\
SFI & - & - & $0.48^{* *}$ \\
\hline
\end{tabular}




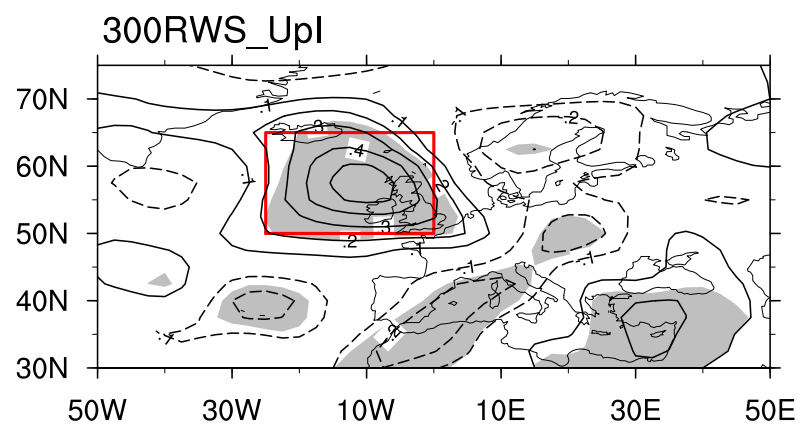

FIG. 10. Regression of the $300-\mathrm{hPa}$ Rossby wave source $\left(10^{-11} \mathrm{~s}^{-2}\right)$ with respect to the normalized UpI. Shading denotes regions that are significant at the $95 \%$ confidence level. The red rectangle represents the defined region of RWSI.

Asia and found it to be very weak (not shown). We attribute this difference between summer and autumn to the different latitudes of the Asian jet. The jet is located relatively far to the north in summer and thus the teleconnection pattern along the jet does not change the tropical and subtropical circulations over the WNP.

\section{Conclusions and discussion}

We investigated the interannual variability of the frequency of TC landfall over East Asia in autumn during the time period of 1958-2014. Our results indicate that the frequencies of TC landfall in the southern and northern coastal regions, which are distinguished by landfall locations to the south and north of $25^{\circ} \mathrm{N}$, respectively, are roughly independent. Therefore we separately examined the large-scale circulation anomalies associated with the frequencies of TC landfall in the southern and northern regions and investigated the possible factors affecting these circulation anomalies.

Higher frequency of TC landfalls over the southern region was closely related to the easterly steering-flow anomalies extending from the tropical WNP westward to southern China and Indochina. These anomalous steering flows are part of the wave train from East Asia to North America in the upper troposphere and the cyclonic anomaly over the SCS in the lower troposphere. Furthermore, the increase of TC landfalls over the southern region is also associated with negative SST anomalies in the equatorial central and eastern Pacific and positive SST anomalies over the western Pacific and Maritime Continent, which is consistent with previous studies on the relationship between the ENSO and TC landfalls in the WNP (e.g., Liu and Chan 2003; Wu et al. 2004). Based on the local anomalous SST-vertical velocity relationship, we suggest that these SST anomalies induce strong convective heating over the tropical western Pacific and Maritime Continent and then trigger the easterly steering-flow anomalies over the tropical WNP, which favor more TC landfalls over the southern region.

By contrast, the frequency of TC landfall over the northern region is closely linked to the meridional steering-flow anomalies over the WNP. The steeringflow anomalies are significantly affected by a teleconnection pattern in the upper troposphere roughly along the westerly jet over Eurasia. Further analysis indicates that the anomalous Rossby wave source over the North Atlantic may trigger this teleconnection.

The present results may have an implication for seasonal forecasting of TCs and even rainfall. The predictability of seasonal TC activity mainly comes from slowly evolving climate signals, such as the ENSO and other tropical SST anomalies (e.g., Zhan et al. 2012; Camp et al. 2015; Manganello et al. 2016; Wang et al. 2016; C. Li et al. 2017). Our results indicate that the frequency of TC landfall over the southern region, which is mainly affected by the ENSO, is more predictable than the frequency of landfall over the northern region, which is mainly related to the extratropical circulation. Therefore specific research is required on the predictability of TC landfall in the southern region in autumn. Considering that the TC landfall in the southern region contributes greatly to the amount of autumn rainfall over southern China, Indochina, and the Philippines, the predictability of the landfall in the southern region is an important source of the reliable seasonal prediction of rainfall over these regions. On the other hand, in comparison with the southern region, the vulnerability of the northern region is relatively high due to less opportunity to be hit by a TC. Hence the predictability of TC landfall in the northern region is also of great socioeconomic significance. Currently, most studies on the predictability of TCs in East Asia and the WNP have been for the summer months (e.g., Wang et al. 2013; Bett et al. 2018; Lin et al. 2018), therefore specific research on the predictability of TCs in autumn will help toward a comprehensive understanding of the variability of TCs in the active seasons, as well as improving the prediction of rainfall in autumn.

Acknowledgments. We are grateful to the two anonymous reviewers for their helpful comments that significantly improved the manuscript. This work was supported by the National Natural Science Foundation of China (Grant 41721004).

\section{REFERENCES}

Bett, P. E., and Coauthors, 2018: Seasonal forecasts of the summer 2016 Yangtze River basin rainfall. Adv. Atmos. Sci., 35, 918926, https://doi.org/10.1007/s00376-018-7210-y. 
Camargo, S. J., A. W. Robertson, S. J. Gaffney, P. Smyth, and M. Ghil, 2007a: Cluster analysis of typhoon tracks. Part I: General properties. J. Climate, 20, 3635-3653, https://doi.org/ 10.1175/JCLI4188.1.

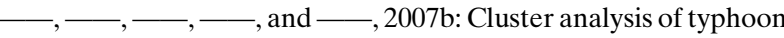
tracks. Part II: Large-scale circulation and ENSO. J. Climate, 20, 3654-3676, https://doi.org/10.1175/JCLI4203.1.

Camp, J., M. Roberts, C. MacLachlan, E. Wallace, L. Hermanson, A. Brookshaw, A. Arribas, and A. A. Scaife, 2015: Seasonal forecasting of tropical storms using the Met Office GloSea5 seasonal forecast system. Quart. J. Roy. Meteor. Soc., 141, 2206-2219, https://doi.org/10.1002/qj.2516.

_ - and Coauthors, 2019: The western Pacific subtropical high and tropical cyclone landfall: Seasonal forecasts using the Met Office GloSea5 system. Quart. J. Roy. Meteor. Soc., 145, 105116, https://doi.org/10.1002/qj.3407.

Chan, J. C., and W. M. Gray, 1982: Tropical cyclone movement and surrounding flow relationships. Mon. Wea. Rev., 110, 13541374, https://doi.org/10.1175/1520-0493(1982)110<1354: TCMASF $>2.0 . \mathrm{CO} ; 2$.

Choi, K. S., C. C. Wu, and E. J. Cha, 2010: Change of tropical cyclone activity by Pacific-Japan teleconnection pattern in the western North Pacific. J. Geophys. Res., 115, D19114, https:// doi.org/10.1029/2010JD013866.

Chu, P. S., 2004: ENSO and tropical cyclone activity. Hurricanes and Typhoons: Past, Present, and Potential, R. J. Murnane and K. B. Liu, Eds., Columbia University Press, 297-332.

Colbert, A. J., B. J. Soden, and B. P. Kirtman, 2015: The impact of natural and anthropogenic climate change on western North Pacific tropical cyclone tracks. J. Climate, 28, 1806-1823, https://doi.org/10.1175/JCLI-D-14-00100.1.

Corporal-Lodangco, I. L., L. M. Leslie, and P. J. Lamb, 2016: Impacts of ENSO on Philippine tropical cyclone activity. J. Climate, 29, 1877-1897, https://doi.org/10.1175/JCLI-D-1400723.1.

Elsner, J., and K. Liu, 2003: Examining the ENSO-typhoon hypothesis. Climate Res., 25, 43-54, https://doi.org/10.3354/ cr025043.

Enomoto, T., 2004: Interannual variability of the Bonin high associated with the propagation of Rossby waves along the Asian jet. J. Meteor. Soc. Japan, 82, 1019-1034, https://doi.org/ 10.2151/jmsj.2004.1019.

Fiorino, M., and R. L. Elsberry, 1989: Some aspects of vortex structure related to tropical cyclone motion. J. Atmos. Sci., 46, 975-990, https://doi.org/10.1175/1520-0469(1989)046<0975: SAOVSR $>2.0 . \mathrm{CO} ; 2$

Fudeyasu, H., S. Iizuka, and T. Matsuura, 2006: Impact of ENSO on landfall characteristics of tropical cyclones over the western North Pacific during the summer monsoon season. Geophys. Res. Lett., 33, L21815, https://doi.org/10.1029/ 2006GL027449.

Gao, S., Z. Chen, and W. Zhang, 2018: Impacts of tropical North Atlantic SST on western North Pacific landfalling tropical cyclones. J. Climate, 31, 853-862, https://doi.org/10.1175/JCLID-17-0325.1.

Goh, Z. C. A., and J. C. Chan, 2010: An improved statistical scheme for the prediction of tropical cyclones making landfall in South China. Wea. Forecasting, 25, 587-593, https://doi.org/10.1175/ 2009WAF2222305.1.

He, H., J. Yang, D. Gong, R. Mao, Y. Wang, and M. Gao, 2015: Decadal changes in tropical cyclone activity over the western North Pacific in the late 1990s. Climate Dyn., 45, 3317-3329, https://doi.org/10.1007/s00382-015-2541-1.
Holland, G. J., 1993: Tropical cyclone motion [chapter 3]. Global Guide to Tropical Cyclone Forecasting, World Meteorological Organization Tech. Doc. WMO/TD 560, Tropical Cyclone Programme Rep. TCP-31, 337 pp.

Hong, X., and R. Lu, 2016: The meridional displacement of the summer Asian jet, Silk Road Pattern, and tropical SST anomalies. J. Climate, 29, 3753-3766, https://doi.org/10.1175/ JCLI-D-15-0541.1.

,$- \ldots$, and S. Li, 2018: Asymmetric relationship between the meridional displacement of the Asian westerly jet and the Silk Road Pattern. Adv. Atmos. Sci., 35, 389-396, https://doi.org/ 10.1007/s00376-017-6320-2.

Hoskins, B. J., and T. Ambrizzi, 1993: Rossby wave propagation on a realistic longitudinally varying flow. J. Atmos. Sci., 50, 1661-1671, https://doi.org/10.1175/1520-0469(1993)050<1661: RWPOAR $>2.0 . \mathrm{CO} ; 2$.

Huang, R., and W. Li, 1987: Influence of the heat source anomaly over the tropical western Pacific on the subtropical high over East Asia. Proc. Int. Conf. on the General Circulation of East Asia, Chengdu, China, Institute of Atmospheric Physics, Chinese Academy of Sciences, 40-51.

Kim, H., J. Kim, C. Ho, and P. Chu, 2011: Pattern classification of typhoon tracks using the fuzzy $c$-means clustering method. J. Climate, 24, 488-508, https://doi.org/10.1175/2010JCLI3751.1.

Kim, J.-H., C. Ho, H. Kim, C. Sui, and S. K. Park, 2008: Systematic variation of summertime tropical cyclone activity in the western North Pacific in relation to the Madden-Julian oscillation. J. Climate, 21, 1171-1191, https://doi.org/10.1175/ 2007JCLI1493.1.

Kim, J.-S., R. C. Y. Li, and W. Zhou, 2012: Effects of the PacificJapan teleconnection pattern on tropical cyclone activity and extreme precipitation events over the Korean Peninsula. J. Geophys. Res., 117, D18109, https://doi.org/10.1029/ 2012JD017677.

Kumar, A., M. Chen, and W. Wang, 2013: Understanding prediction skill of seasonal mean precipitation over the tropics. J. Climate, 26, 5674-5681, https://doi.org/10.1175/JCLI-D-12-00731.1.

Kurihara, K., and T. Tsuyuki, 1987: Development of the barotropic high around Japan and its association with Rossby wave-like propagations over the North Pacific: Analysis of August 1984. J. Meteor. Soc. Japan, 65, 237-246, https://doi.org/10.2151/ jmsj1965.65.2_237.

Li, C., R. Lu, and G. Chen, 2017: Promising prediction of the monsoon trough and its implication for tropical cyclone activity over the western North Pacific. Environ. Res. Lett., 12, 074027, https://doi.org/10.1088/1748-9326/aa71bd.

Li, R. C., W. Zhou, C. M. Shun, and T. C. Lee, 2017: Change in destructiveness of landfalling tropical cyclones over China in recent decades. J. Climate, 30, 3367-3379, https://doi.org/ 10.1175/JCLI-D-16-0258.1.

Lin, X., C. Li, R. Lu, and A. A. Scaife, 2018: Predictable and unpredictable components of the summer East Asia-Pacific teleconnection pattern. Adv. Atmos. Sci., 35, 1372-1380, https://doi.org/10.1007/s00376-018-7305-5.

Liu, K. S., and J. C. Chan, 2003: Climatological characteristics and seasonal forecasting of tropical cyclones making landfall along the South China coast. Mon. Wea. Rev., 131, 1650-1662, https://doi.org/10.1175//2554.1.

Liu, Y., P. Huang, and G. Chen, 2019: Impacts of the combined modes of the tropical Indo-Pacific sea surface temperature anomalies on the tropical cyclone genesis over the western North Pacific. Int. J. Climatol., 39, 2108-2119, https://doi.org/ 10.1002/joc.5938. 
Lu, R., J. H. Oh, and B. J. Kim, 2002: A teleconnection pattern in upper-level meridional wind over the North African and Eurasian continent in summer. Tellus, 54A, 44-55, https:// doi.org/10.1034/j.1600-0870.2002.00248.x.

Manganello, J. V., and Coauthors, 2016: Seasonal forecasts of tropical cyclone activity in a high-atmospheric-resolution coupled prediction system. J. Climate, 29, 1179-1200, https:// doi.org/10.1175/JCLI-D-15-0531.1.

Mei, W., and S. P. Xie, 2016: Intensification of landfalling typhoons over the northwest Pacific since the late 1970s. Nat. Geosci., 9, 753-759, https://doi.org/10.1038/ngeo2792.

Nitta, T., 1987: Convective activities in the tropical western Pacific and their impact on the Northern Hemisphere summer circulation. J. Meteor. Soc. Japan, 65, 373-390, https://doi.org/ 10.2151/jmsj1965.65.3_373.

_, T. Maruyama, and T. Motoki, 1986: Long-term variations of tropospheric circulations in the western Pacific region as derived from GMS cloud winds. J. Meteor. Soc. Japan, 64, 895911, https://doi.org/10.2151/jmsj1965.64.6_895.

Park, D. S. R., C. H. Ho, J. H. Kim, and H. S. Kim, 2011: Strong landfall typhoons in Korea and Japan in a recent decade. J. Geophys. Res., 116, D07105, https://doi.org/10.1029/ 2010JD014801.

Riehl, H., and N. M. Burgner, 1950: Further studies of the movement and formation of hurricanes and their forecasting. Bull. Amer. Meteor. Soc., 31, 244-253, https://doi.org/10.1175/15200477-31.7.244.

Sardeshmukh, P. D., and B. J. Hoskins, 1988: The generation of global rotational flow by steady idealized tropical divergence. J. Atmos. Sci., 45, 1228-1251, https://doi.org/10.1175/15200469(1988)045<1228:TGOGRF>2.0.CO;2.

Wang, B., and J. C. Chan, 2002: How strong ENSO events affect tropical storm activity over the western North Pacific. J. Climate, 15, 1643-1658, https://doi.org/10.1175/15200442(2002)015<1643:HSEEAT>2.0.CO;2.

_ B. Xiang, and J. Y. Lee, 2013: Subtropical high predictability establishes a promising way for monsoon and tropical storm predictions. Proc. Natl. Acad. Sci. USA, 110, 2718-2722, https://doi.org/10.1073/pnas.1214626110.

Wang, C., L. Wang, X. Wang, D. Wang, and L. Wu, 2016: Northsouth variations of tropical storm genesis locations in the Western Hemisphere. Geophys. Res. Lett., 43, 11367-11374, https://doi.org/10.1002/2016GL071440.

Wang, H. J., and K. Fan, 2007: Relationship between the Antarctic oscillation in the western North Pacific typhoon frequency.
Chin. Sci. Bull., 50, 1251-1257, https://doi.org/10.1007/S11434007-0040-4.

Wang, L., and G. H. Chen, 2018: Impact of the spring SST gradient between the tropical Indian Ocean and western Pacific on landfalling tropical cyclone frequency in China. $A d v$. Atmos. Sci., 35, 682-688, https://doi.org/10.1007/s00376-0177078-2.

Wu, C., and K. A. Emanuel, 1995: Potential vorticity diagnostics of hurricane movement. Part I: A case study of Hurricane Bob (1991). Mon. Wea. Rev., 123, 69-92, https://doi.org/10.1175/ 1520-0493(1995)123<0069:PVDOHM > 2.0.CO;2.

Wu, L., and B. Wang, 2004: Assessing impacts of global warming on tropical cyclone tracks. J. Climate, 17, 1686-1698, https://doi.org/ 10.1175/1520-0442(2004)017<1686:AIOGWO>2.0.CO;2.

- , and X. Chen, 2016: Revisiting the steering principal of tropical cyclone motion in a numerical experiment. Atmos. Chem. Phys., 16, 14 925-14 936, https://doi.org/10.5194/acp-1614925-2016.

_- B. Wang, and S. Geng, 2005: Growing typhoon influence on East Asia. Geophys. Res. Lett., 32, L18703, https://doi.org/ 10.1029/2005GL022937.

Wu, M. C., W. L. Chang, and W. M. Leung, 2004: Impacts of El Niño-Southern Oscillation events on tropical cyclone landfalling activity in the western North Pacific. J. Climate, 17, 1419-1428, https://doi.org/10.1175/1520-0442(2004)017<1419: IOENOE $>2.0 . \mathrm{CO} ; 2$.

Wu, R., B. P. Kirtman, and K. Pegion, 2006: Local air-sea relationship in observations and model simulations. J. Climate, 19, 4914-4932, https://doi.org/10.1175/JCLI3904.1.

Zhan, R., Y. Wang, and M. Ying, 2012: Seasonal forecasts of tropical cyclone activity over the western North Pacific: A review. Trop. Cyclone Res. Rev., 1, 307-324, https://doi.org/ 10.6057/2012TCRR03.07.

Zhang, Q., L. Wu, and Q. Liu, 2009: Tropical cyclone damages in China 1983-2006. Bull. Amer. Meteor. Soc., 90, 489-495, https://doi.org/10.1175/2008BAMS2631.1.

Zhang, W., H. F. Graf, Y. Leung, and M. Herzog, 2012: Different El Niño types and tropical cyclone landfall in East Asia. J. Climate, 25, 6510-6523, https://doi.org/10.1175/JCLI-D-1100488.1.

Zhou, X., R. Lu, and G. Chen, 2018: Impact of interannual variation of synoptic disturbances on the tracks and landfalls of tropical cyclones over the western North Pacific. $A d v$. Atmos. Sci., 35, 1469-1477, https://doi.org/10.1007/s00376-0188055-0. 